\title{
TRWANIE RZECZY I TRWANIE KULTURY
}

\section{ROBERT PIŁAT}

\author{
Wydział Filozofii Chrześcijańskiej Uniwestytetu Kardynała Stefana Wyszyńskiego w Warszawie; \\ Faculty of Philosophy of the Christian Cardinal Stefan Wyszynski University in Warsaw (Poland) \\ r.pilat@uksw.edu.pl
}

Wytwory kultury stwarzają dwie nieskończoności, których nie zna przyroda. Pierwszą zauważył Thomas Mann we wstępie do Józefa i jego braci. Badając artefakty, symbole i ludzkie obyczaje, instynktownie szukamy ich źródeł, wierząc, że w ten sposób lepiej je zrozumiemy. Ale nigdy nie dochodzimy do źródła ostatecznego - odsłaniając kolejne antecedencje i starając się je zrozumieć, kierujemy się z konieczności ku jeszcze dawniejszym zdarzeniom i treściom, a potem ku jeszcze wcześniejszym. „Im głębiej człowiek wnika, im dalej po omacku sięga w podziemny świat przeszłości, tym bardziej niezgłębione okazują się początki człowieczeństwa, początki jego dziejów, obyczajności, cofając się przed naszą sondą coraz to na nowo i coraz dalej w bezdenność"'. Mann nazwał to zjawisko studnią przeszłości i zdumiewającym paradoksem, jako że owa nieskończoność genezy istnieje przecież w skończonym czasie, który dany był człowiekowi na Ziemi. Druga nieskończoność zmierza w odwrotnym kierunku, ku przyszłości i związana jest $\mathrm{z}$ nieodwołalnością zdarzenia historycznego. W przyrodzie poprzednie zdarzenia przechodzą w kolejne i jedynie w tych drugich istnieją, całkowicie przez nie pochłonięte, lecz zdarzenie ludzkie, stan rzeczy obdarzony sensem, nie zna końca. Kiedy już powstało, kolejne zdarzenia nie mogą go wymazać. Filozof Karl Raimund Popper doszedł nawet do radykalnego wniosku, że

${ }^{1}$ T. Mann, Józef i jego bracia, t. 1, tłum. E. Sicińska, Warszawa 1988, s. 5. 
byty posiadające sens mają odrębny sposób istnienia i ukuł dla nich nazwę Świat ${ }_{3}$, odróżniając go od Świata (przedmioty fizyczne) i Świata $_{2}$ (procesy psychiczne $)^{2}$. Jednak Popperowski Świat ${ }_{3}$ nie trwa w czasie, jego wiecznotrwałość wynika raczej z istnienia poza czasem. Francuski filozof i muzykolog, Vladimir Jankélévitch, ujął tę samą zagadkę inaczej, włączając w nią czas i trwanie: „Skoro zaistniał, nie może już nie być: ów tajemniczy i niepojęty fakt, że zaistniał, staje się jego wiatykiem na wieczność"3. Nie uczynił jej przez to łatwiejszą, lecz poniekąd pełniejszą. Trwanie kultury u Poppera jest sprawą poznania nakierowanego na bezczasowe sensy, podczas gdy u Jankélévitcha obejmuje również poczucie historii.

Uczono nas w szkole historii tak, jakby była ciągiem fizycznych zdarzeń, pomiędzy którymi zalega pustka. Wiemy jednak, że po wielkich bitwach i sławnych aktach założycielskich mijały zwykłe dni, godziny i minuty ludzkiego życia. Pustka oddziela historyczne świadectwa - co stanowi zmorę historyków - lecz nie istnieje pustka dziejów. Te bowiem trwają nie tylko w przemijających zdarzeniach i ich podlegających zniszczeniu reprezentacjach: dokumentach, artefaktach. Owe brakujące dni i godziny możemy czasem dostrzec, odkrywając je w zwykłych rzeczach nieafiszujących się swoją funkcją świadectwa. W nich historia istnieje w sposób wprawdzie utajony, lecz doskonale ciągły. Kiedy minęła ostania wojna światowa, wiele prostych zdarzeń i rzeczy uzyskało nowe znaczenie - straciło niewinność i nie mogło już powrócić do dawnych sensów: pukanie do drzwi, mur, pociąg, kanał, las, piwnica, drut kolczasty, barak. W polskich filmach $\mathrm{z}$ lat pięćdziesiątych (np. w reżyserii Wojciecha Hasa czy Jerzego Kawalerowicza) kamera często patrzy na rzeczy w ten sposób podejrzliwie, z lękiem, że skryty w nich świat okrucieństwa nagle się obudzi,

${ }^{2}$ Zob. K.R. Popper, Wiedza obiektywna, thum. A. Chmielewski Warszawa 1992, s. 206-216.

${ }^{3}$ Za P. Ricoeur, Pamięć, historia, zapomnienie, thum. J. Margański, Kraków 2006, motto do książki. 
jakby życie uwikłane w owo trwanie historii w rzeczach nie mogło wrócić do równowagi ${ }^{4}$.

W felietonie Zbigniewa Herberta napisanym w roku 1951 w związku z nowymi odkryciami archeologicznymi na terenie Gdańska pojawiają się trzy skutki archeologicznej rekonstrukcji przedmiotów ${ }^{5}$. Pierwszy polega na przywracaniu tego, co zostało zniszczone przez czas. Stanowi podniesiony do rangi sztuki odwieczny konflikt człowieka z czasem, stawianie oporu, o którym tak sugestywnie pisał Roman Ingarden w eseju Człowiek i przyroda:

Twory kultury wytworzone przez człowieka nie stanowią niczego więcej jak tylko pewnego rodzaju cień rzeczywistości, będąc jedynie tworami czysto intencjonalnymi. Noszą na sobie tylko pozór istnienia, który charakteryzuje wszelkie duchowe dzieła człowieka, jak dzieła sztuki lub rozmaite inne wytwory kultury ludzkiej, bez względu na to, czy są dziełami poszczególnego człowieka czy też całej społeczności ludzkiej. Konstytuują się one na podłożu rzeczy i procesów przyrodzonego świata, przystosowanych do tego przez człowieka, a ich własności przekraczają granice uposażenia rzeczy materialnych, pokrywając je nową warstwą sensu i nowych zjawisk. Transcendując tym te rzeczy, tracą zarazem pełnię i autonomię istnienia i nie posiadają mocy rzeczywistości niezależnej od człowieka i jego aktów duchowych. Mogą one zaspokoić aspiracje człowieka do życia wzniesionego ponad przyrodę jedynie pod warunkiem jego nadzwyczajnej duchowej aktywności i zapadają z powrotem w zupełny niebyt, skoro tylko człowiek traci wolę transcendowania swej prostej natury przyrodzonej i wyrzeka się swej twórczej aktywności świadomości. ${ }^{6}$.

Herbert zaś tak opisuje scenę, która zrobiła na nim wielkie wrażenie:

Przez uchylone drzwi widać pracownię naukową bezimiennych twórców Muzeum. Nad ogromną stertą drobniutkich odłamków, wyglądających jak rozsypana mozaika, pochylają się głowy i bystre palce wyciągają oto

${ }^{4}$ Por. R. Piłat, Wartość milczenia, „Kwartalnik Filmowy” 2000, nr 29-30.

${ }^{5} \mathrm{Z}$. Herbert, Muzealne klopoty i nadzieje. Węzet gordyjski oraz inne pisma rozproszone, Warszawa 2001, s. 633.

${ }^{6}$ R. Ingarden, Człowiek i przyroda, [w:] Książeczka o człowieku, Kraków 1973, s. 17. 
ostatni kawałek XVIII-wiecznego talerza. Teraz subtelny ornament niebieskich kwiatów zajaśniał całym blaskiem. Mądre palce przywróciły [wyróżnienie - R.P.] kruchej sztuce jej dawną urodę.

Innym sensem trwania rzeczy jest u Herberta przetrwanie. Poetę fascynowały procesy, które w szczęśliwych warunkach pozwalają rzeczom istnieć znacznie dłużej, niżby to wynikało z naturalnego biegu rzeczy:

W grodzie poziom higieny nie był wysoki, a sterty nieczystości zalegające ulice, wraz z wilgocią, odpadkami kory - dawały garbnik, betulinę i metan, dzięki czemu przechowało się [wyróżnienie: R.P.] lepiej i więcej, niż w innych grodach wczesnośredniowiecznych w Polsce, takich rzeczy jak: barwne tkaniny, szczątki roślin i zwierząt, włosie, pióra, a także kurze jajko, nad którym toczą się zażarte spory zwiedzających, czy to możliwe.

W tym samym fragmencie Herbert dostrzega trzeci aspekt trwania - w ludzkim poznaniu i rozumieniu: „Są to przedmioty z pozoru błahe, lecz naprawdę pozwalają gtęboko wniknąć [wyróżnienie: R.P.] w strukturę społeczną, ekonomiczną, kulturalną i polityczną tamtych czasów"7. Wszystkie trzy spostrzeżenia poety zaskakują pewnym pozytywistycznym duchem i wiarą w potęgę wiedzy i technicznej maestrii, która pozwala wydzierać historii jej uśpione i, zdawałoby się, już niedostępne tajemnice. Przez odtworzenie, przechowanie, poznanie zawłaszczamy tę samą historię, która nas stworzyła. Próby zrozumienia historii wiążą się jednak z głębokim paradoksem. Zawłaszczyć własną genezę to jakby zawłaszczyć samego siebie, lecz nasz stosunek do samych siebie nie da się opisać jako posiadanie. Jest to oczywiście jedna z metafor, które towarzyszyły wiekom refleksji filozoficznej, wyraża zażyłość z samym sobą, bycie przyjacielem samego siebie. Nie jest jednak najszczęśliwszą metaforą, ponieważ wytwarza nieskończony regres posiadania tego, kto posiada tego, kto posiada itd. Człowiek posiadający sam siebie

\footnotetext{
${ }^{7}$ Tamże, s. 646.
} 
okazuje się na zawsze przed sobą ukryty i właśnie z tego powodu paradygmat poznawczy nie do końca spełnił nadzieje w regulowaniu ludzkiego obcowania z historią. Spojrzenie, które kieruje się na przedmioty kultury, zawiera w sobie bogatszą hermeneutykę. W istocie, w późniejszej twórczości Herberta obcowanie z kulturowymi artefaktami zyskuje inną funkcję. Nie jest już zadaniem poznawczym, wydzieraniem przeszłości jej zagadek, lecz jest raczej, jak pisze poeta w tomie Mistrz z Delft, poszukiwaniem znaków, śladów utraconej wspólnoty. Również słowo „przedmiot” we wcześniejszym sławnym tomiku poetyckim Studium przedmiotu nawiązuje do pracy artysty lub osoby dramatu, a nie odkrywcy - przedmiot pojawia się bez reszty zanurzony w ludzkim losie.

Artefaktem, który trwa w najbardziej zagadkowy i osobliwy sposób, jest książka. Jej fizyczna forma wydaje się dziś, w dobie pamięci elektronicznych, tylko jednym z możliwych nośników tekstu i obrazu, dlatego wielu prorokuje jej zmierzch. Jednak ten zmierzch nie następuje. Przeciwnie, fizyczna szata książki pociąga miłośników lektury, wydawców, plastyków - jest materią poznania i ekspresji, niesprowadzalną do samego tekstu. Dlatego nie ustaje też pasja przywracania świetności dawnym zwojom, kodeksom i tomom. Materialność książki jest bowiem bardzo szczególna: trwa ona w czasie jak inne artefakty, lecz z drugiej strony tekst w niej zawarty ma swój własny czas - ten, w którym trwają znaczenia, idee i style. Oba te składniki książki odwołują się do odmiennych struktur czasowych, lecz jedna w jakiś sposób wspiera drugą. Wydaje się, że pokryta patyną czasu powłoka książki stanowi wskazówkę dla czytelnika, a może jego bezwiedną antycypację - oto oczekuje z napięciem na wyłonienie się tekstu nie tylko z kart książki, lecz także z głębi dziejów. Niech pewna anegdota zilustruje tę zależność: piszący te słowa studiował filozofię w miejscu, gdzie dzisiaj pracuje, w dawnej ATK, i tu też przesiadywał w czytelni nad lekturami. Pewnego razu z magazynu wydobyto zamówioną książkę, dwutomowy angielski komentarz do Immanuela Kanta. Wystarczyło uchylić okładkę, by odkryć, że karty książki 
pozostały przez całe stulecie nierozcięte. Pieczęcie pokazywały, że ten wydany pod koniec XIX wieku tom należał do biblioteki w Królewcu, skąd powędrował do powojennej Polski, pokrywając się pieczęciami nowych bibliotek, skreślanymi starannie i zastępowanymi innymi, kiedy książka zmieniała miejsce pobytu. Wreszcie trafiła na warszawskie Bielany - gruby wolumin przenoszony z mozołem i katalogowany, lecz nie czytany przez nikogo ${ }^{8}$. Co się czuje, rozcinając takie karty? Jakiej treści się oczekuje? Odkrycia zapoznanego geniusza? Bezwartościowej grafomanii? Jakkolwiek by było, nie jest to zwykła lektura - pod przewodnictwem pożółkłego papieru i wyblakłego grzbietu książka zaprasza do poważnej rozprawy z historią.

Działaniom konserwatorów towarzyszy poszukiwanie oryginału. On to stoi na straży prawdy, która, jak wiadomo, rodzi się w umyśle, lecz właśnie przed arogancją umysłu trzeba ją chronić - przed jego skłonnością do fantazjowania, spekulacji i zawłaszczania odkrywanych sensów. Pojęcie oryginału jest jednak nieostre. W dziedzinie grafiki występuje na przykład pojęcie pośmiertnego oryginału, czyli odbitek wykonanych po śmierci artysty z przygotowanej przez niego matrycy. Jednak nawet w tak osobliwym przypadku czyni się wysiłki, by dokonać subtelnych rozróżnień, pozwalających na utrzymanie intuicji oryginału. Dobrym przykładem jest trwający kilka lat europejski program, który ma na celu zbadanie oryginalności grafik Rembrandta będących w posiadaniu poznańskiego muzeum. Kuratorka wystawy wieńczącej te wysiłki, Grażyna Hałasa, opowiada w wywiadzie dla Programu II Polskiego Radia o tytanicznej pracy, subtelnych technikach i błyskotliwych dedukcjach, które doprowadziły do zdetronizowania kilku pozycji i podniesienia do rangi oryginału kilku innych. Słuchacz nie ma wątpliwości, że ta praca była nie tylko pasjonująca, lecz także

${ }^{8}$ Niestety, pomimo wysiłków zawodnej pamięci nie jestem w stanie zwieńczyć tej anegdoty efektowną puentą i podać tytułu dzieła. Trzydzieści lat, które minęło od tamtej chwili, pochłonęło notatki, świadomość tytułu i autora dzieła. Sądzę jednak, że niektórzy czytelnicy - miłośnicy lektury - przypomną sobie własne podobne odkrycia. 
owocna. Ale o jaki owoc tu chodzi? Osiągniecie nie leży przecież w samym tylko ustaleniu procesu przyczynowego czy materialnego pierwszeństwa jednego artefaktu w stosunku do innego. Podobnie jak w wypadku starej książki, odkrycie oryginału (lub ,zdemaskowanie” kopii) jest raczej nicią przewodnią rozumienia - zwiastuje treść, otwiera uprawnioną (i upragnioną) drogę do interpretacji. Temu fenomenowi otwarcia towarzyszą silne emocje, tworzące gatunek sam dla siebie - można je nazwać przeżyciem oryginału. Jak napisał Tim Hitchcock w eseju Digital Searching and the Re-formulation of Historical Knowledge:

Kiedy rozwijasz pergaminowy dokument zawierający dwustuletnie zeznania składane $\mathrm{w}$ śledztwie prowadzonym przez koronera i piasek, który użyto do osuszenia atramentu wysypuje się na twoje ręce, trudno jest zachować odpowiedni dystans [...]. Jeżeli [jednak] uznamy, że tylko bezpośredni kontakt $\mathrm{z}$ oryginałem ma pełną wartość, redukujemy zasięg oddziaływania archiwów wyłącznie do wąskiej grupy specjalistów, muzeów - do osób, które mogą przyjść na wystawę (są w stanie kupić bilet i dostać się na miejsce), bibliotek - do osób, które otrzymają możliwość wzięcia rozpadającego się kodeksu do rąk $\mathrm{k}^{9}$.

Relacja emocjonalna, o której pisze Hitchcock, choć realna i autentyczna, ma jednak dość efemeryczny status. Trudno ją dokładnie scharakteryzować, zmierzyć, oszacować jej znaczenie. Czy powinna być zatem wyznacznikiem decydującym o tym, że to oryginał, a nie kopia ma pozostać paradygmatem dostępu do kultury? Marcin Wilkowski formułuje w tej sprawie wątpliwości, włączając się w żywą współczesną dyskusję na wspomniany temat ${ }^{10}$.

Napisałem powyżej, że w poszukiwaniu oryginału nie chodzi o czysto retrospektywny akt ustalania przyczynowości, lecz o prospektywny akt

${ }^{9}$ Za: M. Wilkowski, Kopia lepsza od oryginatu, ,, Historia i media”, 13.03.2012, http:// historiaimedia.org/2012/03/13/kopia-lepsza-od-oryginalu/ [data dostępu: 2.11.2015]

${ }^{10}$ Tamże. 
otwierania nowej interpretacji. Przyczynowość w naukach przyrodniczych wiąże te dwa aspekty - na tym właśnie polega jej wartość poznawcza. Ustalając prawidłowości, które miały miejsce wcześniej, daje możliwość przewidywania. Podobnie jest $\mathrm{w}$ badaniach kultury, chociaż bez mostu w postaci równań matematycznych. I tu przyczynowość podaje swoistą nić Ariadny w pracy interpretacji.

Są inne, prócz przyczynowości, ontyczne własności świata, które w poszukiwaniu oryginału mają ogromne znaczenie. Pierwszą jest to $\dot{s}$ samość badanych obiektów w czasie. Gdyby brać rzeczywistość materialną w jej całości, problem tożsamości byłby trywialny - stwierdzałoby się ją apriorycznie, ponieważ świat, w którym wszystko się zmienia, jest przecież jako całość ze sobą tożsamy. Lecz w odniesieniu do pojedynczych przedmiotów, dzieł, osób problem ciągłości okazuje się bardzo trudny. Od wieków filozofowie zastanawiali się, w którym momencie zmieniający się część po części przedmiot przestaje być tym samym przedmiotem. Nie ustawały próby rozwiązania zagadek, jak ta ze statkiem, który w trakcie remontu otrzymuje nowe poszycie, wręgi, pokład, maszty i urządzenia, a pomimo to jest (a zdaniem niektórych nie jest) tym samym statkiem. W nowszych czasach pytanie to w poważniejszym kontekście odnowił brytyjski filozof Derek Parfit, argumentując w szeroko dyskutowanej książce Reasons and Persons, że w filozofii człowieka i moralności nie potrzebujemy kategorii tożsamości osobowej - wystarczy stopniowalna i nieprzechodnia kategoria ciągłości.

Ostatnią kategorią, która związana jest z poszukiwaniem oryginału jest źródtowość. Oryginal jest nie tylko nicią przewodnią w poszukiwaniu interpretacji, lecz także kieruje do jej źródła. Wracamy tu poniekąd do cytowanej na początku tych rozważań uwagi Thomasa Manna o studni czasu. Poszukujący rozumienia umysł instynktownie kieruje się ku genezie - chodzi mu nie tylko o początek, lecz o miarodajny punkt odniesienia. Poszukiwanie to może się stać obsesyjne i doprowadzić do przekonania, że to, co istotne, już było, że cała prawda leży w przeszłości, zaś powinnością 
współczesnych jest tylko jej przyswojenie i przechowanie. Ale nie trzeba ulegać obsesji, by uszanować ideę źródłowości. Wystarczy uznać normatywną funkcję przeszłych form kultury, które dla każdej nowej formacji stanowią zadanie - dlatego, że były. Historia to dzieje normatywnego odnoszenia się do źródeł - podejmowanie i łamanie zobowiązań z tych źródeł płynących, ich zawężanie, rozszerzanie - ogólnie biorąc: reinterpretacja. W dziedzinie twórczości zjawisko to opisał Harold Bloom jako lęk przed wpływem - dramatyczną pracę poety, który musi zbudować swoją oryginalność z niewłasnej poetyckiej materii języka, symbolu i stylu ${ }^{11}$.

$\mathrm{W}$ procesie normatywnego przyswajania i oswajania kultury osobliwa rola przypada światu rzeczy. Interesujące spojrzenie na tę kwestię zaproponował francuski filozof Michel Foucault. Był on wpływowym krytykiem pojęcia podmiotowości, które uważał za sztuczny konstrukt, służący bardziej celom społecznej kontroli niż kształtowaniu własnego życia. Uważał ludzką podmiotowość za wymyślony wewnętrzny punkt widzenia, dzięki któremu przypisuje się osobom sprawczość i odpowiedzialność za ich wypowiedzi, czyny, postawy czy gesty. Samym osobom narzuca to z kolei silny nakaz samopoznania, które pozwala uczestniczyć w tej społecznej grze kontroli na równych prawach. Podmiot to ktoś, kto wie, co i dlaczego uczynił, a przez to jest w stanie zmierzyć się ze społeczną oceną, czasem przeciwstawiając się jej, a o wiele częściej poddając się jej i stosując do siebie zewnętrzne osądy. Foucault zaproponował zmianę optyki: zamiast ustalania prawd o s o b i e o sensie i wartości swoich doświadczeń, czynów i relacji z innymi - trzeba przedstawić sobie życie jako zbiór technik, dzięki którym tworzymy samych siebie $^{12}$. Foucault twierdził, że jednostronny nacisk na poznawanie samego siebie pozbawia wartości inne rejestry kierowania samym sobą, a tym samym

${ }^{11}$ H. Bloom, The Anxiety of Inluence. A Theory of Poetry, Oxford 1997.

${ }^{12}$ M. Foucault, Techniki siebie, [w:] idem, Filozofia, historia, polityka. Wybór pism, tłum. D. Leszczyński i L. Rasiński, Warszawa 2000. 
pozbawia życia tego, co tradycyjnie nazywano decorum - kulturowych dyspozycji, cech, zdolności, stanów przyjemności i nawyków, a one wszystkie przyczyniają się do pożądanej formy życia. Otóż ważną częścią owego decorum jest świat ludzkich wytworów - wytworów kultury. W filozofii Foucaulta znika wprawdzie podmiot, lecz dzięki badaniu kultury możliwe jest wytyczenie pewnej 1 i n i i, a tę równie dobrze można nazwać linią podmiotową - ciągu zamkniętych w rzeczach treści, które wytworzyły dzisiejszych nas, z naszą zdolnością rozumienia świata i działania. Innymi słowy, tworzenie samego siebie jest jak tworzenie kultury - wymaga subtelności, zestawiania przedmiotów, nawigowania wśród stylów, wydarzeń, spajania własnych doświadczeń więzami motywacji, przyczynowości. Nie sposób podać reguł tego procesu. Jest on sztuką, w której można się doskonalić, lecz której ostatecznych zagadek nie da się poznać - i to nie dlatego, że są głęboko ukryte, lecz dlatego, że ich nie ma. Sztuka bycia sobą nie jest szyfrem zapisanym w kulturze, niczym kryptogram, lecz jest po prostu sztuką bycia w kulturze. Foucault podsumował w ten sposób pewien nurt obecny w europejskiej myśli już od renesansu, szczególnie wyraźnie wyrażony w Próbach jego imiennika, Michela Montaigne'a.

Technika kształtowania siebie sprawia, że rzeczy stają się świadkami kultury, a ta z kolei staje się samą istotą człowieka. Osobiście uważam diagnozę Foucaulta za przesadną, ponieważ sądzę, że jeśli wyzbędziemy się metafizyki człowieka (jakkolwiek nieuchwytnej) i zastąpimy ją kulturą, nie utrzymamy zdolności normatywnego myślenia. To jednak temat na osobną dyskusję. W obecnych uwagach chciałem podkreślić tylko to, co w tej diagnozie jest mądre i twórcze. Pokazuje ona, że nasze życie wśród rzeczy dalekie jest od jednowymiarowego pragmatyzmu. Rzeczy są świadkami i strażnikami sensu potrzebnego do życia. Ta ich funkcja nie znika nawet wtedy, gdy ulegają fizycznemu unicestwieniu. Wciąż pozostaje po nich miejsce w przestrzeni znaczenia. Wydaje się, że nie tylko wykształceni badacze kultury, lecz po prostu ludzie szukający intensywnego przeżycia i rozumienia świata 
znajdują upodobanie w kontemplacji tego, czego już nie ma. Dawniej były to przede wszystkim ruiny, jako znak tego, co było - oryginał, dostępny wprawdzie w ułamkach, lecz w całej materialnej prawdzie. Dziś ta forma przeżywania świata jeszcze się wysubtelniła: błądzimy po nieistniejących miastach, nakładamy stare mapy na dzisiejsze obszary, wyobrażamy sobie zniesione już granice, widzimy zburzone mury warszawskiego getta i berlińskiego muru, oglądamy osieroconą bazę kolumny w zburzonym przez napoleońskie wojska kościele w Cluny, patrzymy w puste niebo po World Trade Center. Myślę, że dla osób, które poświęciły się rozumieniu i zachowaniu materialnej kultury otwierają się nowe pola działania. Umieszczanie przeszłości w obrębie teraźniejszości nie jest już ani zwykłym odczytywaniem tekstów, ani przechowywaniem materialnych rzeczy, lecz uobecnieniem i dawaniem świadectwa.

\section{BIBLIOGRAFIA}

Harold Bloom, The Anxiety of Inluence. A Theory of Poetry, Oxford University Press, Oxford 1997.

Michel Foucault, Filozofia, historia, polityka. Wybór pism, thum. D. Leszczyński i L. Rasiński, PWN, Warszawa 2000.

Zbigniew Herbert, Muzealne kłopoty i nadzieje. Węzet gordyjski oraz inne pisma rozproszone, Więź, Warszawa 2001.

Roman Ingarden, Ksiązeczka o człowieku, Wydawnictwo Literackie, Kraków 1973. 
Thomas Mann, Józef i jego bracia, t. 1, thum. E. Sicińska, Czytelnik, Warszawa 1988.

Robert Piłat, Wartość milczenia, „Kwartalnik Filmowy” 2000, nr 29-30.

Karl Raimund Popper, Wiedza obiektywna, tłum. A. Chmielewski, PWN, Warszawa 1992.

Paul Ricoeur, Pamięć, historia, zapomnienie, thum. J. Margański, Universitas, Kraków 2006.

Marcin Wilkowski, Kopia lepsza od oryginatu, „Historia $i$ media”, 13.03.2012, http://historiaimedia.org/2012/03/13/kopia-lepsza-od-oryginalu/ [data dostępu: 2.11.2015]. 


\section{Preserving Things and the Persistence of Culture}

This article discusses the relation between temporal existence of things and the persistence of culture. The material and the immaterial aspects of culture are quite different in relation to time. According to philosopher Karl R. Popper, meanings, senses and ideas belong to a separate quasi-temporal realm of being. They come about in time but henceforth they exist non-temporarily. Their existence, unlike that of physical objects, does not depend on keeping a delicate balance between the change and identity - it is not based on struggle against time. But on the other hand, their seemingly atemporal subsistence is strictly connected to the temporal existence of things. The latter do not carry meaning in virtue of sheer convention, but rather by means of subtle connection between their material structure and the properties of sentient and intelligent beings. Books hold a very special place in this framework. The physical properties of books are intertwined with their content very strongly albeit mysteriously. It is safe to say that reducing books to their content - by conveying the content to digital carriers alone - would result in a serious impoverishing of culture. In reference to early journalist works by poet Zbigniew Herbert, three functions of preserving and studying artefacts are distinguished: reconstruction, preserving and learning. In such studies there is always a quest for originals and considerable efforts are made in order to distinguish them from copies and derivatives. The article gives a brief account of recent debate concerning the value of these pursuits. Finally a discussion with Michel Foucault is presented, concerning the role of things in self-formation.

Keywords: artefact, preservation, original, history, Zbigniew Herbert, Michel Foucault. 


\section{Nowości Wydawnictwa UKSW}

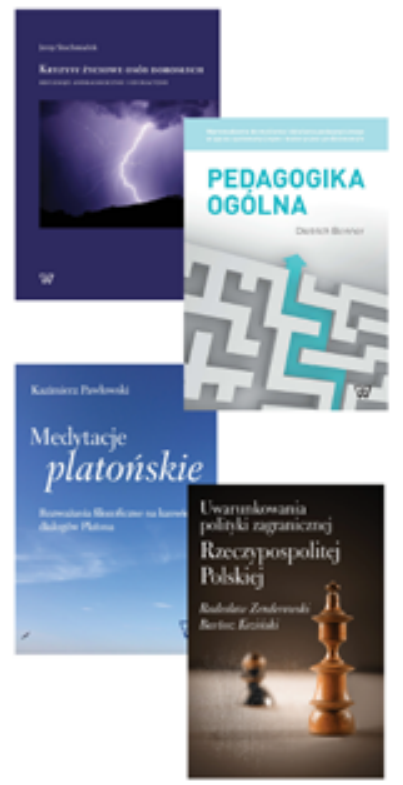

- Jerzy Stochmiałek, Kryzysy życiowe osób dorosłych

- Dietrich Benner, Pedagogika ogólna

- Kazimierz Pawłowski, Medytacje platońskie. Rozważania filozoficzne na kanwie dialogów Platona

- Bartosz Koziński, Radosław Zenderowski, Uwarunkowania polityki zagranicznej Rzeczypospolitej Polskiej

Więcej informacji na stronie: www.wydawnictwo.uksw.edu.pl 